\title{
RHINOLOGY
}

\section{Endoscopic repair of nasal septal perforation}

\author{
Riparazione della perforazione del setto nasale con tecnica endoscopica \\ M. CASSANO \\ Department of Otorhinolaryngology, University of Foggia, Italy
}

\begin{abstract}
SUMMARY
Surgical closure of nasal septal perforation is one of the most challenging procedures in nasal surgery. During the last decade, many endoscopic repair techniques have been described with a success of post-operative repair between $76.4 \%$ and $100 \%$. The advantages of this approach are its minimal invasiveness (with no external scars), optimal exposure of the operative field (with better visibility of structures) and good control of perforation margins. The drawbacks are that it is time-consuming and can be difficult to perform, requiring years of endoscopic experience. In this review, all the relevant literature published in which repair was completely made endoscopically is overviewed, comparing the success rates, diameter of the perforation and materials used for the repair.
\end{abstract}

KEY WORDS: Nasal septal perforations $\bullet$ Nasal endoscopy $\bullet$ Septal perforations repair $\bullet$ Endoscopic techniques

\section{RIASSUNTO}

La riparazione della perforazione del setto nasale rappresenta delle più complesse procedure chirurgiche nasali. Nel corso dell'ultimo decennio, sono state descritte numerose tecniche endoscopiche di riparazione, con una percentuale di successo variabile fra il $76.4 \%$ e $100 \%$. I vantaggi di questa tecnica sono la mini-invasività (nessuna cicatrice esterna), un'ottima esposizione del campo operatorio (con una migliore visualizzazione delle strutture anatomiche) e un buon controllo visivo dei margini della perforazione. Possibili svantaggi sono un maggior tempo operatorio ed una maggiore difficoltà di esecuzione che richiede curve di apprendimento di anni. In questa review riportiamo l'esperienza di numerosi lavori pubblicati sulla riparazione endoscopica delle perforazioni del setto nasale, mettendo a confronto la percentuale di successo, il diametro della perforazione e i materiali utilizzati per la riparazione.

PAROLE CHIAVE: Perforazione del setto nasale $\bullet$ Endoscopia nasale $\bullet$ Riparazione di perforazioni settali $\bullet$ Tecnica endoscopica

Acta Otorhinolaryngol Ital 2017;37:486-492

\section{Introduction}

Nasal septal perforation is an anatomical defect of the cartilaginous and/or bone nasal septum (Fig. 1). In many cases it is asymptomatic, but when symptomatic patients have recurrent epistaxis, nasal crusting, whistling, headache, dryness, and nasal obstruction. Anterior perforations are generally symptomatic, while posterior ones are not symptomatic as the inspired air is rapidly humidified by the nasal mucosa, preventing dryness ${ }^{1}$.

Only symptomatic perforations require treatment to relieve symptoms. Medical treatment with nasal irrigation and ointments can only reduce crusting, dryness and nasal obstruction in mild symptomatic perforations.

A useful alternative is mechanical closure with a prosthesis such as the septal button ${ }^{2}$. Silicon buttons can alleviate epistaxis, whistling and nasal obstruction, but these prostheses cannot control the production of crusting around the margins of the button which causes discomfort for patients ${ }^{3}$. New silicon buttons ${ }^{2}$ and magnet-based buttons ${ }^{4}$ reduce the patient's discomfort and crusting.

If these treatments are unsuccessful, surgical treatment is recommended. Many surgical techniques for septal perfo- ration repair have been reported, but most are technically difficult, require experienced surgeons and are associated with a relatively low rate of success, as demonstrated by the high number of re-perforations ${ }^{5}$.

The major problems in the surgical approach are due to the tenuous nature of the tissues and to the limited surgical exposure of the area ${ }^{6}$. Moreover, many techniques proposed require graft harvesting, with a consequent morbidity of the donor site (temporalis fascia, conchal cartilage, mastoid periosteum, fascia lata, etc.), or an allograft (acellular human dermal graft, porcine small intestine mucosa) with possible rejection ${ }^{7}$.

The reported surgical approaches include external rhinoplasty, midfacial degloving, unilateral hemitransfixion and closed endonasal techniques ${ }^{7}$. The advantage of the latter is that they do not leave any external scar, but are more difficult to perform due to the narrow operating field. "Open" techniques offer a wider operating field, thus allowing better access to the superior and posterior margins of the perforation.

During the last decade, many studies have described optimal results with closed endoscopic techniques ${ }^{18-21}$. By 
using the endoscope, excellent visualisation and exposure can be achieved without excessive dissection and with good control of septal perforation margins ${ }^{15}$. The drawback of these techniques is that they require good endoscopic skills (and so may be more difficult to achieve for less experienced surgeons) and a longer operating time ${ }^{9}$. Herein, the techniques of endoscopic repair of nasal septal perforation underlining the advantages and disadvantages of each technique, comparing the success rate, are reviewed. The review includes all studies published in which the repair was completely made endoscopically. Studies with endoscopice control of a single stage of surgery (harvesting of the flap or graft, control of haemostasis) were excluded.

\section{Review of the literature}

In 2002, Hier at al. first reported the use of nasal endoscope in a case of 27-year-old man with a $2 \times 2 \mathrm{~cm}$ anterior nasal septal perforation that was repaired by a superiorly based rotation advancement flap associated with an interposition graft containing a mixture of bone and cartilage harvested from the septum. The graft was positioned in a pocket between the two mucosal flaps extending between the medial crura to hold the graft. The drawback of this technique was the presence of exposed bone/cartilage graft on the right side of the nose, which was covered by a Gelfilm splint. The authors reported only small amounts of crusting on the exposed cartilage, with a complete mucosalisation and healing of the septum after 7 months of follow-up. Hier underlined the excellent visualisation and exposure achieved by the endoscopic technique without excessive dissection and with excellent teaching capabilities ${ }^{8}$.

The second report of an endoscopic repair of nasal septal perforation was by Ayshford et al. in 2003. The authors reported a series of 17 patients with symptomatic anterior perforation ranging from $1 \mathrm{~cm}$ to $2.5 \mathrm{~cm}$ in diameter who were submitted to endoscopic repair with an acellular human dermal allograft (alloderm) and an anteriorly based inferior turbinate flap. After excising the edges of the perforation and raising the mucopericondrial flaps around the margins of the perforation, unilateral (in small perforations) or bilateral (in large ones) inferior turbinate flaps were created endoscopically by incising the inferior turbinate posterior to the perforation and mobilising it on an anteriorly based pedicled flap. An acellular human dermal allograft was then positioned, after rehydratation, between the cartilage and mucoperichondrial flap and sutured with vicryl. Finally, the inferior turbinate flap was sutured to the anterior half of the perforation edge. The technique achieved successful closure of the perforation in 13 cases $(76.5 \%)$. In two cases, a smaller residual perforation developed owing to persistent crust picking, in the other two cases the graft failed. The disadvantages of this technique are the cost of the alloderm and the need for a second stage surgery after 3 weeks, as the inferior turbi- nate flap needs to be divided and sutured to the posterior edge of the perforation ${ }^{1}$.

In 2004, Meghachi et al. published in the French literature their technique of endoscopic repair of nasal perforation using a unilateral posterior pedicled mucosal rotation flap without interposition material, reporting a $75 \%$ success rate in a series of 11 cases. The case series also included perforations larger than $2 \mathrm{~cm}$ in diameter ${ }^{9}$.

In 2007, Presutti et al. described their personal technique of nasal septal repair based on bilateral dissection of monopedicled mucosal flaps from nasal fossa floor sutured at the edge of the perforation without any interposition graft between the two mucosal layers. He prepared the flaps endoscopically (with a four-hand endoscopic approach), with an anterior caudal septal incision, extended laterally, to the floor of nasal fossa, and posteriorly, under the inferior turbinate proximal to the choana. The mucoperiostium and the mucopericondrium from the incision up to the perforation edge is elevated and the posteriorly based flap is transposed medially and pushed cranially to cover the perforation. The flap is then sutured to the mucosa of the upper edge of the perforation. This procedure is performed on the other side creating a double layer repair. This technique allowed complete repair in 28 (of 31) patients $(90.3 \%$ ) with better results in perforation smaller than $3 \mathrm{~cm}(26 / 27$ patients; $96.3 \%$ ). The authors underline the advantage of the endoscopic view in flap dissection and suturing, and the absence of donor site morbidity with their technique ${ }^{10}$.

Lee et al. also reported in 2008 an endoscopic technique with unilateral advancement mucosal flaps and a temporalis fascia on the other side. The flaps were obtained by an hemitrasfixion incision extended laterally under the inferior turbinate and another horizontal incision made on the septal dorsum. The mucoperiostium and mucopericondrium were then elevated to create two flaps that advance (one upward and the other downward) to cover the perforation before suturing with 5.0 vicryl. The authors underline the advantages of the unilateral mucosal flap in avoiding the enlargement of the perforation and developing new perforations during surgery, as well as decreased operation time while performing a one stage procedure ${ }^{11}$.

In 2011, four authors published personal techniques for endoscopic nasal septal repair.

Mansour treated 6 patients with a free graft harvested from the inferior turbinate and applied between the mucoperichondrium of both septum sides. At 2-year followup, 5 patients had complete repair $(83 \%)$ and one partial repair, with a resolution of symptoms in all cases. This technique has the advantage to be very simple without the necessity of flap creation, but allows only a one-layer repair of the septal perforation ${ }^{12}$.

In contrast, Giacomini et al. proposed a three-layer endoscopic reconstruction of the septum. They performed a hemitrasfix incision and elevation of the mucoperichondrial and mucoperiostal layers on both sides from the anterior septum 
to the choana and until the nasal floor. After the scarification of perforation margins, the elevated flaps were advanced bilaterally (primarily in a horizontal plane) in an inverted sliding flap manner. Vertical or horizontal relaxation incision may be added to achieve a better mobilisation and to make vertical advancement. An interposition graft of auricular conchal autologous cartilage was inserted between the two flaps. With this approach, the authors reported complete repair in 10 large $(2-4 \mathrm{~cm})$ perforations with a success rate of $71.4 \%$ and symptom improvement in 12 patients $(85.7 \%)^{13}$. In the same year, Kazkayasi and Yalcinozan described a case report in which the nasal perforation was endoscopically repaired using an over-projected uncinate process. Actually, the technique contemplated caudal septal incision with elevation of mucoperichondrium through the nasal floor up to the roof of the nasal cavity and suture of the margins of the perforation on one side. On the other side, the mucoperiostium of the resected uncinate process is sutured with the mucopericondrium of the perforation margin. In this way, the technique guarantees two-layer repair with the use of autologous flap and graft with a potential better integration due to the respiratory epithelium that they possess ${ }^{14}$.

Optimal results with $100 \%$ of repair in 11 perforations ranged between 10 and $25 \mathrm{~mm}$ of diameter were reported by Castelnuovo et al. with their technique of unilateral superiorly based rotational-advancement flap, supplied by the anterior ethmoidal artery. The authors performed an incision vertically along the septum, until reaching the lateral wall of the posterior portion of the inferior meatus. Then, the incision turns horizontally following the inferior meatus until its anterior portion and finally turning upward perpendicular to the septum reaching the inferior border of the perforation. After the elevation, a large superiorly based flap is crated allowing comfortable advancement and sutured to the mucosa around the perimeter of the perforation. In this case, unilateral one-layer technique allowed repair in all cases at the first attempt ${ }^{15}$.

In 2012, Tastan et al. described an endoscopic technique of septal perforation repair using an inferior turbinate composite graft. They harvested the graft from the middle part of the inferior turbinate (leaving the shape and volume of the inferior turbinate), obtaining a three-layer graft with bone attached with its mucosa on both surfaces. The graft must be slightly larger than perforation size so that it can be easily overlapped without tension to the perforation margins and is sutured to them with 5.0 absorbable sutures. In case of medium and large perforations (>10 mm), a bipedicled mucosal advancement flap ${ }^{22}$ can be added with flaps elevated from the nasal floor bilaterally and from the nasal roof unilaterally, and sutured to the composite inferior turbinate graft. Using this technique, the authors achieved complete repair in 24 (88.8\%) of 27 patients with just two failures in medium sized perforations and one in a large perforation. The advantages of this technique are ease of development and insertion of

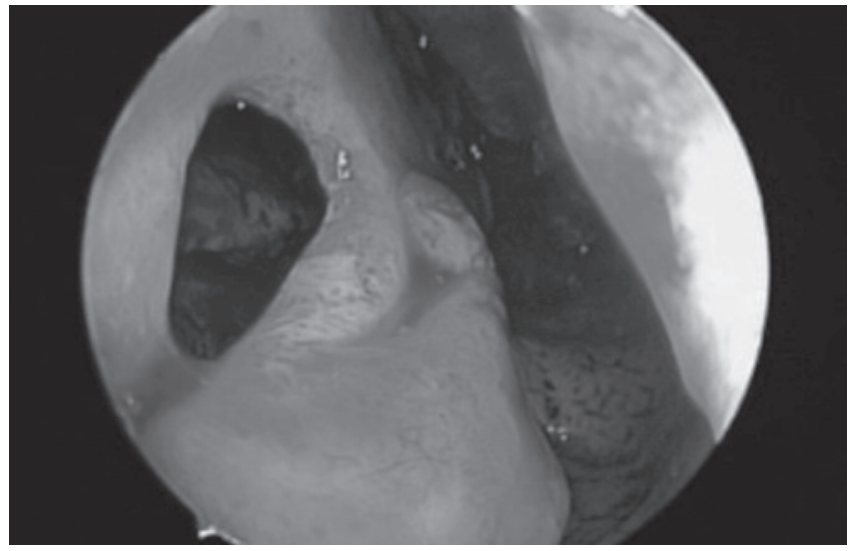

Fig. 1. A septal perforation of the cartilaginous part of the septum.

the graft, three layer repair, single stage procedure and the possibility to combine with bilateral flaps to reduce mucosal tension ${ }^{16}$.

In the same year, Lee DH and colleagues reported on the usefulness of the anterior pedicled inferior turbinate flap for endoscopic repair of septal perforation and reconstruction of mucosal defects following excision of a septal tumor. In a small cohort of only 6 cases, the authors reported a success rate of $83.3 \%$ without any case of full-thickness necrosis of the flap, and no excessive crusting or empty nose syndrome. Finally, they underlined the considerable learning curve of endoscopic preparation of the flap, but the potential improvement of treatment outcomes of reconstruction when the familiarity with these flap will increase ${ }^{17}$.

In 2012, Chen described an endoscopic sandwich technique for repair of septal perforation with diameters of 1-2 $\mathrm{cm}$. The technique contemplates the use of three layers of interposition graft with cartilage (residual septum cartilage) or bone (vomer or perpendicular plate of ethmoid) in the middle with quadriceps fascia covering both sides of the graft. The size of the entire composite graft should be more than twice the size of the perforation. This triplelayer interposition graft is interposed between two mucopericondrium and mucoperiosteal flaps elevated from the residual septal mucosa starting from an anterior columellar incision. In cases of perforation about $2 \mathrm{~cm}$, a middle turbinate mucoperiosteal graft can be added in an on-lay fashion on one side of the nasal septum to cover the perforation and the sandwich graft. Biological glue is then applied to increase the adhesiveness between the various components of the graft and the mucosa. Using this technique, the authors achieved a $92.3 \%$ success rate with just one case of partial repair ( $3 \times 3 \mathrm{~mm}$ residual perforation) but without symptoms. The authors underlined the necessity of adding septal or nasal floor mucosal flaps in case of perforation larger than $2 \mathrm{~cm}$ because a simple graft could cause central necrosis in the absence of adequate blood supply ${ }^{18}$.

In 2014, we described a new endoscopic technique called "slide and patch" because it combines a mucoperiosteal 
Table I. Publications on endoscopic techniques of nasal septal perforation repair: A brief description of the technique , number of patients, dimension of the perforation and repair rate are reported.

\begin{tabular}{|c|c|c|c|c|c|}
\hline Author, year & Technique & No. patients & $\begin{array}{l}\text { Size of } \\
\text { perforation }\end{array}$ & $\%$ success & Notes \\
\hline Hier, 2002 & $\begin{array}{l}\text { Superiorly based rotation } \\
\text { advancement flap associated with } \\
\text { an interposition graft containing } \\
\text { a mixture of bone and cartilage } \\
\text { harvested from the septum }\end{array}$ & 1 & $2 \times 2 \mathrm{~cm}$ & 100 & $\begin{array}{l}\text { Case report. Two layer repair } \\
\text { Drawback: the presence of } \\
\text { exposed bone/cartilage graft on } \\
\text { the right side of the nose, that } \\
\text { was covered just by a Gelfilm } \\
\text { splint }\end{array}$ \\
\hline Ayshford, 2003 & $\begin{array}{l}\text { Unilateral or bilateral anteriorly } \\
\text { based inferior turbinate flap + } \\
\text { alloderm }\end{array}$ & 17 & $1-2.5 \mathrm{~cm}$ & 76.4 & $\begin{array}{l}\text { Two - three layer repair. } \\
\text { Drawback: cost of Aloderm } \\
\text { and the need for second stage } \\
\text { surgery to divide and suture } \\
\text { inferior turbinate }\end{array}$ \\
\hline Meghachi, 2004 & $\begin{array}{l}\text { Unilateral posterior pedicled } \\
\text { mucosal rotation flap without } \\
\text { interposition material }\end{array}$ & 11 & $0.5->2 \mathrm{~cm}$ & 75 & $\begin{array}{l}\text { One layer repair. Success also in } \\
\text { large perforations }(>2 \mathrm{~cm})\end{array}$ \\
\hline Presutti, 2007 & $\begin{array}{l}\text { Bilateral monopedicled mucosal } \\
\text { flaps from nasal fossa floor sutured } \\
\text { at the edge of the perforation } \\
\text { without any interposiztion graft }\end{array}$ & 31 & $<3 \mathrm{~cm}$ & 90.3 & Two layer repair \\
\hline Lee, 2008 & $\begin{array}{l}\text { Unilateral advancement mucosal } \\
\text { flaps + temporalis fascia on the } \\
\text { other side }\end{array}$ & 14 & $0.7-2 \mathrm{~cm}$ & 85.7 & Two layer repair \\
\hline Mansour, 2011 & Inferior turbinate free graft & 6 & $<2 \mathrm{~cm}$ & 83 & Very simple. One layer repair. \\
\hline Kazkayasi, 2011 & $\begin{array}{l}\text { Over-projected uncinate process } \\
\text { graft + mucosal sutures }\end{array}$ & 1 & $0.7 \times 1 \mathrm{~cm}$ & 100 & Case report. Two layer repair \\
\hline Giacomini, 2011 & $\begin{array}{l}\text { Bilateral bipedicled horizontal } \\
\text { advancement flaps - choncha } \\
\text { cartilage interposition graft. }\end{array}$ & 14 & $2-4 \mathrm{~cm}$ & 85.7 & $\begin{array}{l}\text { Three layer repair. Improvement } \\
\text { of symptoms in } 12 \text { patients }\end{array}$ \\
\hline Castelnuovo,2011 & $\begin{array}{l}\text { Unilateral superiorly based } \\
\text { rotational-advancement flap , } \\
\text { supplied by the anterior ethmoidal } \\
\text { artery }\end{array}$ & 11 & $1-2.5 \mathrm{~cm}$ & 100 & One layer repair. \\
\hline Tastan, 2012 & $\begin{array}{l}\text { Inferior turbinate composite graft } \\
\text { (bone + mucosa) }\end{array}$ & 27 & $0.4-3.2 \mathrm{~cm}$ & 88.8 & $\begin{array}{l}\text { Three layer graft. Can be } \\
\text { combined with flaps elevated } \\
\text { from the nasal floor bilaterally }\end{array}$ \\
\hline Chen, 2012 & $\begin{array}{l}\text { Sandwich technique (interposition } \\
\text { graft with cartilage or bone in the } \\
\text { middle with quadriceps fascia } \\
\text { covering both sides }\end{array}$ & 13 & $1-2 \mathrm{~cm}$ & 92 & $\begin{array}{l}\text { Three layer graft . A forth layer } \\
\text { can be added with a middle } \\
\text { turbinate mucoperiosteal graft }\end{array}$ \\
\hline Lee, 2012 & $\begin{array}{l}\text { Unilateral or bilateral anterior } \\
\text { pedicled inferior turbinate flap }\end{array}$ & 6 & $1-3 \mathrm{~cm}$ & 83.3 & One-two layer repair \\
\hline Cassano, 2014 & $\begin{array}{l}\text { "Slide and patch" technique : } \\
\text { inferior turbinate mucoperiosteal } \\
\text { free graft + mucosal rotational or } \\
\text { advancement flap }\end{array}$ & 22 & $<0.5-3.5 \mathrm{~cm}$ & 95.4 & Two layer repair \\
\hline Hanci, 2014 & $\begin{array}{l}\text { Unilateral superiorly based middle } \\
\text { turbinate mucosa flap }\end{array}$ & 31 & $<2 \mathrm{~cm}$ & 93.5 & One layer repair \\
\hline Kaya, 2015 & $\begin{array}{l}\text { Interposition graft made with a } \\
\text { piece of conchal cartilage covered } \\
\text { on both sides by temporalis fascia }\end{array}$ & 22 & $<2 \mathrm{~cm}$ & 86.3 & Three layer graft \\
\hline
\end{tabular}

free graft of the inferior turbinate with a mucosal rotational or advancement flap from nasal septum. The technique involves an initial bilateral trimming of perforation margins with wide dissection all around the perforation from the underlying cartilage or bone. Next, through a hemitransfix in- cision, the mucopericondrial and mucoperiosteal layers are extensively elevated on one side of the nasal septum, and a mucoperiosteal graft harvested from the inferior turbinate is inserted in the tunnel between the septal cartilage and the elevated septal mucoperichondrial flap and positioned un- 


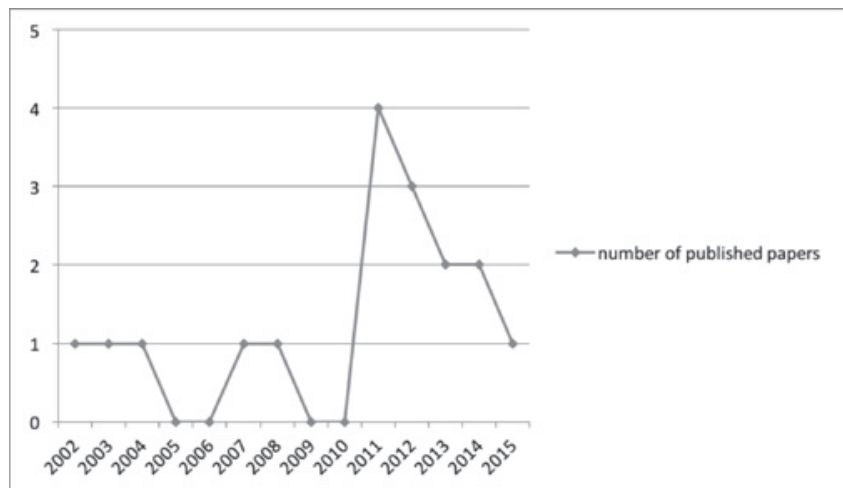

Fig. 2. Number of publications on endoscopic techniques of septal perforation repair from 2002 to 2015.

der the previously elevated perforation borders in underlay fashion for a minimum of $5 \mathrm{~mm}$ all around.

On the other side, in oval perforations with the horizontal large diameter, a horizontal incision the same length as the perforation large diameter is performed on nasal mucosa $1 \mathrm{~cm}$ from the dorsal border of septal cartilage. The mucopericondrial flap is then elevated from the perforation margin up to the incision, the flap is transposed downward and the borders of the perforation are sutured together with a 5.0 Vycril suture.

In the case of rounded perforations, a rotation/advancement mucoperiosteal flap is designed by a rounded incision based posteriorly and elevated up to the choana. Even in this case, the flap, based on the nasal-septal artery, is rotated in order to reach the inferior border of the perforation. In both cases the flap should advance to cover the perforation without tension. The use of a flap of native septal tissue (with the advantage of the rich vascular supply and proximity to the defect), with an interposition graft of inferior turbinate, provided optimal results with a success rate of $95.4 \%$ in 22 patients and just 1 case of partial closure ${ }^{19}$.

In the same year, Hanci and Altun reported their experience with a unilateral middle turbinate mucosal flap. This was a monopedicled, superiorly-based bone included conchal flap, with which the authors achieved complete endoscopic repair in 29 of 31 patients without any other symptoms in the postoperative period ${ }^{20}$.

The last reported technique of endoscopic nasal septal perforation repair was published in 2015 by Kaya et al. The authors repaired 19 of 22 septal perforations (success rate $86.3 \%$ ) using an interposition graft made with a piece of conchal cartilage (at least $3 \mathrm{~mm}$ larger than perforation) covered on both sides by temporalis fascia. The graft was placed into the perforation endoscopically (after elevating the edges for 3-4 $\mathrm{mm}$ around the perforation) and stabilised with bioreadsorbable staples. The authors conclude that their technique is expected to allow better healing and mucosal resurfacing ${ }^{21}$ (Table I).



Fig. 3. Number of publications on open, closed and endoscopic techniques of septal perforation repair in the last three decades.

\section{Discussion}

Although numerous surgical techniques have been described, the surgical closure of nasal septal perforations is still challenging for the surgeon and operating techniques are not yet standardised. In a review of various studies on nasal septal perforation repair, reporting an extensive range of surgical techniques, Goh found that the results were rarely statistically significant ${ }^{7}$. This can be explained by the scant experience of almost all surgeons with this surgery: in fact, very few authors have reported on a large number of operations in their study ${ }^{15}$.

Numerous techniques have been proposed, such as external, intranasal, endoscopic, midfacial degloving or sublabial approach, with the use of various grafts (synthetic or autograft) and combined flaps (unilateral or bilateral), and each has its advantages and disadvantages.

The endoscopic endonasal approach has gained ground in the last decades with the studies of Hier and Ayshford ${ }^{18}$. From these first reports, many studies have been published, reporting a percentage of post-operative repair variables between $76.4 \%{ }^{1}$ and $100 \%{ }^{15}$.

The increasing interest on endoscopic techniques is certified by the increasing number of papers published in the last few years. In fact, 10 publications (of 15) were published in the last 5 years (from 2011) (Fig. 2).

As is shown in figure 3 , the trend of septal perforation repair techniques has completely changed in the last three decades: from 1986 to 1996 an open approach (open rhinoplasty, midfacial degloving, etc.) was the favorite approach with just three publications about a closed approach. In the decade 1996-2006, open and closed approaches had the same numbers of publications and an endoscopic approach began to be described. In the last decade, closed approaches were prominent, together with a large number of publications $(\mathrm{n}=12)$ on endoscopic approaches (Fig. 3)

The advantages of this approach are its minimal invasiveness (with no external scars), optimal exposure of the op- 
erative field (with better visibility of the structures) and good control of perforation margins. The drawbacks are that it is time-consuming and can be quite difficult to perform, requiring some years of endoscopic experience. The use of an endoscopic approach has allowed very high percentage of success even in cases of unilateral flap repair ${ }^{9121520}$, which is classically considered insufficient by some authors ${ }^{1323}$. In fact, Kridel stated that "a septal perforation is a hole in 3 distinct contiguous layers composed of both right and left septal mucoperichondrial flaps and the intervening cartilage, all 3 of which must be separated from each other and repaired individually" ${ }^{24}$. Nevertheless, Castelnuovo reported $100 \%$ of nasal perforation repair with only an anterior ethmoidal artery unilateral septal flap without any interposition graft ${ }^{15}$. The unilateral nasal flap has the advantage of avoiding enlargement of the perforation and development of any other perforations during the operation, as well as decreased surgical time since only a one stage procedure is performed ${ }^{11}$.

In an evaluation of the predictive factors for the outcomes of nasal septal perforation repair, some authors reported that repair with bilateral flaps is the most important factor for successful closure ${ }^{25}{ }^{26}$. Notwithstanding, with these techniques these authors did not reach the success rate of endoscopic techniques using only one flap and a graft 8101119 .

However, the interposition graft could be useful because it serves not only as a scaffold for the migration of respiratory mucosa, but also provides a second layer of protection.

Although Moon stated that the kind of graft material does not dictate the success of surgery ${ }^{26}$, the use of autologous nasal mucosa grafts has many advantages. First of all, it enables complete maintenance of normal nasal physiology since it integrates perfectly with the septal nasal mucosa. In fact, in a previous study, we used a mucoperiosteal graft harvested from the inferior turbinate and the side of this graft exposed during the repair is the respiratory mucosa of the inferior turbinate which perfectly integrates with the remaining septal mucosa ${ }^{19}$. Indeed, the most common failure of autogenous buccal mucosa or skin grafts is dry nose and crusting, since respiratory epithelium is not present ${ }^{27}$. Other endogenous tissues such as temporalis fascia or tragal cartilage can be difficult to handle and to mold into shape, whilst synthetic grafts may have problems of rejection by host tissues ${ }^{15}$. Actually, in most endoscopic techniques an allograft is applied. Only some authors report the use of autologous grafts harvested from the nose with optimal results ${ }^{141619}$.

The use of allograft, such as the Alloderm, has the advantage to eliminate donor site morbidity and to fit in all sizes of perforations, acting as an excellent scaffold for re-epithelialisation, but is associated with high costs ${ }^{1}$.

Other authors report good results in nasal septal perforation repair only with inferior turbinate grafts, with a rate of success between $83 \%$ and $88 \%{ }^{12} 16$. The disadvantage is that its bulk that may cause partial obstruction of the airway. At any rate, the addition of a septal mucopericondrial flap could help to sustain the graft. In fact, especially in larger defects, there is a limited amount of mucosa available to provide vascular supply to the graft. Thus, the process of integration becomes more difficult with larger grafts ${ }^{15}$.

Some authors report that perforation size is one of the principal factors that can lead to failure of the repair technique. Both Moon and Kim reported a higher probability of developing re-perforation after surgery in patients with large perforation size, because size is inversely proportional to the amount of mucosa available for perforation closure ${ }^{25} 26$. In fact, in large perforations, approximating the mucosal flap almost always causes tension in the perforation site. The vertical height of a perforation has been shown to play a more important role in determining the surgical success than the horizontal length because tension between the floor of the nose and the the dorsum was found to be critical ${ }^{22}$. By "large perforation size", this is considered a perforation whose diameter is $<10 \mathrm{~mm}$ for Moon and $<20 \mathrm{~mm}$ for Kim ${ }^{25}{ }^{26}$. In most cases, endoscopic techniques have been used in small-to-medium perforations $(0.5-2 \mathrm{~cm})$, but some report good results even in repair of perforations $>2 \mathrm{~cm}^{13} 16{ }^{19}$. It is obvious that in large perforations the engraftment of the graft is more difficult, but an endoscopic approach enables the surgeon to achieve good precision in graft positioning, respecting the rule that the diameter of the grafted material must exceed that of perforation and all margins must be covered with nasal mucosa surrounding the perforation by at least $1 \mathrm{~cm}$ without tension ${ }^{28}$.

Even for endoscopic techniques the racial criterion has proven to be critical for success in perforation repair. In fact, case series from Oriental authors have shown a lower percentage of success compared to case series by Western authors ${ }^{11} 1718$. This can be explained by the smaller nasal cavity and septum of Asians and therefore by the consequent insufficient viable tissue to cover the perforation site ${ }^{26}$.

\section{Conclusions}

Endoscopic techniques can nowadays be considered the gold standard for septal perforation repair. They cause less trauma and provide a better surgical view, helping the surgeon to close various size perforations even in the posterior part of the septum with a high percentage of success. Notwithstanding the high outcome rates, it is not possible to compare the results with other approaches because the number of patients is usually small, leading to statistically insignificant results. Larger series with multicentre studies are desirable to demonstrate the superiority of endoscopic techniques. 


\section{References}

1 Ayshford CA, Shykhon M, Uppal HS, Et al. Endoscopic repair of nasal septal perforation with acellular human dermal allograft and an inferior turbinate flap. Clin Otolaryngol Allied Sci 2003;28:29-33.

2 Mullace M, Gorini E, Sbrocca M, et al. Management of nasal septal perforation using silicone nasal septal button. Acta Otorhinolaryngol Ital 2006;26:216-8.

3 Osma U, Cüreoðlu S, Akbulut N, et al. The results of septal button insertion in the management of nasal septal perforation. J Laryngol Otol 1999;113:823-4.

4 Teschner M, Willenborg K, Lenarz T. Preliminary results of the new individual made magnet-based nasal septal button. Eur Arch Otorhinolaryngol 2012; 269:861-5.

5 Dosen LK, Haye R. Surgical closure of nasal septal perforation. Early and long term observations. Rhinology 2011;49:486-91.

6 Watson D, Barkdull G. Surgical management of the septal perforation. Otolaryngol Clin North Am 2009;42:483-93.

7 Goh AY, Hussain SS. Different surgical treatments for nasal septal perforation and their outcomes. J Laryngol Otol 2007;121:419-26.

8 Hier MP, Yoskovitch A, Panje WR. Endoscopic repair of a nasal septal perforation. J Otolaryngol 2002;31:323-6.

9 Meghachi AS, Jankowski R, Védrine PO, et al. Endoscopic closure of septal perforations by mucosal rotation flaps. Ann Otolaryngol Chir Cervicofac 2004;121:222-8.

10 Presutti L, Alicandri Ciufelli M, et al. Nasal septal perforations: our surgical technique. Otolaryngol Head Neck Surg 2007;136:369-72.

11 Lee HR, Ahn DB, Park JH, et al. Endoscopic repairment of septal perforation with using a unilateral nasal mucosal flap. Clin Exp Otorhinolaryngol 2008;1:154-7.

12 Mansour HA. Repair of nasal septal perforation using inferior turbinate graft. J Laryngol Otol 2011;125:474-8.

13 Giacomini PG, Ferraro S, Di Girolamo S, et al. Large nasal septal perforation repair by closed endoscopically assisted approach. Ann Plast Surg 2011;66:633-6.

14 Kazkayasi M, Yalcinozan ET. Uncinate process in the repair of nasoseptal perforation. Aesthetic Plast Surg 2011;35:878-81.

15 Castelnuovo P, Ferreli F, Khodaei I, et al. Anterior ethmoidal artery septal flap for the management of septal perforation. Arch Facial Plast Surg 2011;13:411-4.

16 Tastan E, Aydogan F, Aydin E, et al. Inferior turbinate composite graft for repair of nasal septal perforation. Am J Rhinol Allergy 2012;26:237-42.

17 Lee DH, Yoon TM, Lee JK, et al. Clinical utility of the inferior turbinate flaps in the reconstruction of the nasal septum and skull base. J Craniofac Surg 2012;23:322-6.

18 Chen FH, Rui X, Deng J, et al. Endoscopic sandwich technique for moderate nasal septal perforations. Laryngoscope 2012;122:2367-72.

19 Cassano M. Endoscopic repair of nasal septal perforation with "slide and patch" technique. Otolaryngol Head Neck Surg 2014;151:176-8.

${ }^{20}$ Hanci D, Altun H. Repair of nasal septal perforation using middle turbinate flap (monopedicled superiory based bone included conchal flap): a new unilateral middle turbinate mucosal flap technique. Eur Arch Otorhinolaryngol 2015;272:1707-12.

21 Kaya E, Cingi C, Olgun Y, et al. Three layer interlocking: a novel technique for repairing a nasal septum perforation. Ann Otol Rhinol Laryngol 2015;124:212-5.

22 Kridel RW. Septal perforation repair. Otolaryngol Clin North Am 1999; 32:695-724.

23 Schulz-Coulon HJ. Three-layer repair of naso-septal repair. Eur Arch Otorhinolaryngol 2007;264:S265, ric 9.

24 Kridel RW. Considerations in the etiology, treatment, and repair of septal perforations. Facial Plast Surg Clin North Am 2004;12:435-50.

25 Kim SW, Rhee CS. Nasal septal perforation repair: predictive factors and systematic review of the literature. Curr Opin Otolaryngol Head Neck Surg 2012; 20:58-65.

26 Moon IJ, Kim SW, Han DH, et al. Predictive factors for the outcome of nasal septal perforation repair. Auris Nasus Larynx 2011; 38:52-7.

27 Ceylan A, Ileri F, Celenk F, et al. Upper lateral cartilage inner mucoperichondrial flap technique for the repair of nasal septal perforation. ORL J Otorhinolaryngol Relat Spec 2007;69:245-50.

28 Re M, Paolucci L, Romeo R, et al. Surgical treatment of nasal septal perforations. Our experience. Acta Otorhinolaryngol Ital 2006;26:102-9. 